\title{
Online Banking in India
}

\section{Suraj Kumar Rath, Shubham Trivedi, Soumya Chakraborty, Alex Reginald Natal and Sumit Pandey}

Students - 2018-20 Batch, Symbiosis Institute of Business Management Pune, Symbiosis International Deemed University, Pune - 412115, Maharashtra, India

\begin{abstract}
Today a large portion of the keeping money occurs while you are tasting espresso or accepting a vital call. ATMs are at your doorstep. Keeping money administrations are open $24 \times 7$. There are more plastic cards in your wallet than cash notes. A gigantic piece of this change is because of the appearance of IT. Banks today work in a much globalized, changed, privatized and a focused domain. Keeping in mind the end goal to get by in this condition banks need to utilize IT. Indian saving money industry has seen huge advancements because of far-reaching developments that are occurring in the data innovation. Electronic saving money has risen up out of such a creative advancement. The target of the present paper is to think about and dissect the advancement made by Indian keeping money industry in the reception of innovation. The investigation is auxiliary based and diagnostic in nature. The advancement in e-saving money in Indian managing an accounting industry is estimated through different parameters, for example, Computerization of branches, Automated Teller Machines, Transactions through Retail Electronic Payment Methods and so on. Measurable and scientific instruments, for example, basic development rate, rates, and midpoints and so forth are utilized. The paper additionally features the difficulties looked by Indian banks in an appropriation of innovation and proposals are made to handle these difficulties. The paper reasons that in years to come e-managing an account won't just be an adequate method of keeping money however favored method of saving money.
\end{abstract}

Keywords: Banks, Money, Online, Internet

\section{Introduction}

Data Technology has turned into a fundamental apparatus in today's associations. Banks today work in an exceptionally globalized, changed, privatized and an aggressive situation. So as to get by in this condition banks need to utilize IT. IT has presented new business worldview. It is progressively assuming a noteworthy job in enhancing the administrations in the managing an accounting industry. Indian saving money industry has seen a gigantic advancement because of major developments that are occurring in the data innovation. Electronic keeping money has risen up out of such an inventive improvement. Present day innovation is viewed as a panacea for the majority of the ills that the keeping money segment faces today. Indeed, even at present, India is a relative unbanked nation as the credit-to-GDP proportion is one of the most reduced in the creating economies. So banks are confronting the double test of expanding infiltration and high development direction. The managing an accounting industry can take out two targets with one shot that is with help of innovation. Enormous advancement occurred in the field of innovation which has lessened the world to a worldwide town and it has acquired wonderful changes the keeping money industry. Branch saving money in the physical mode has been changed into snap and request channel mode. 


\section{Online Banking in India- A Literature Review}

Web unrest is a worldwide marvel and passing by the present development insights, India expects a spurt in the Internet entrance in coming years especially in the electronic business. It is a conspicuous idea that electronic (Internet) keeping money and installments are probably going to propel pretty much couple with web-based business. Look to demonstrate that Internet managing an account significantly affects the plans of action of banks, securities exchanging firms, business houses, insurance agencies, and so on. Web managing an account has additionally pulled in the consideration of, controllers and administrators in the creating countries since the late 1990s. Bikram Jit Singh Mann \& Sunpreet Kaur Sahni. (2012).

Web managing an account is a reason for worry to the greater part of the disconnected banks that ought to be prepared for a phenomenal rivalry from the nonconventional saving money foundations that offer to keep money and budgetary administrations over the Internet. Albeit a portion of the customary banks has begun offering their administrations online, it is just an expansion of their disconnected administrations. Web managing an account has now begun propelling clients to stop their assets with the online banks, which has a significant effect on the store base of the physical banks.

The utilization of innovation in managing an account has a coordinate associated with the gainfulness. Cetris paribus, interest in electronic managing an account increment the overall revenue of banks by decreasing expenses and increment in non-premium salary, which will build the ROA and ROE. Cost-viability in the conveyance of administrations straight-forwardly infers nearly high customer fulfilment and a resulting change in the income demonstrate for the banks. Selection of the Internet method of managing an account would result in expanded shopper mindfulness, pulls in the passage of worldwide majors in the market and would prompt the development of open guidelines in the saving money industry. The coordination of the keeping money administrations with online business and rise of e-money would emphatically influence the proficiency scores of the banks.

Be that as it may, Internet saving money is a blended gift as an expanded hazard, the level of certainty rested by the customers and the issue of mixing it with the physical framework. Web managing an account has achieved another introduction to dangers like settlement hazard, universal innovation exchange hazard, wrongdoing or misrepresentation chance, administrative shirking hazard, tax assessment evasion hazard, and rivalry chance. Basel II suggestion on operational hazard likewise underpins this speculation. In India, a few banks like HDFC and ICICI have presented instalment entryways running on secure frameworks having firewalls against hacking. Accommodation, security and cost viability are the languages in the range of internet managing an account.

Analysts on different events have raised numerous issues, which must be tended to in the setting of Internet saving money in India. In the first place the accessibility of innovation and foundation to help the new model of saving money. Second the requirement for Internet managing an account itself - Internet Banking or a productive arrangement of prompt keeping money or helpful saving money, Nayak, Raghvendra (2018). Third a satisfactory instrument to handle the security chance and operational hazard angles. Fourth an appropriate lawful system to deal with the rights and commitment of the customers, while the greater part of these issues has been to some degree tended to, a vital issue still remains - what existing and potential shoppers feel about Internet managing an account and based on this how a suitable saving money model can be created in the Indian setting. There is a need to gauge and break down the purchaser discernment towards Internet saving money, to discover what isn't right with customary banks and give a structure to the banks to deliberately receive the Internet in order to augment an incentive for the buyers.

\section{Conclusion}

In India, e-banking is in a relatively nascent stage. Teena, Shivnani. (2015). Presumably, Indian banks are attempting genuine endeavours for the appropriation of trendsetting innovation and establishment of e-conveyance channels yet at the same time, masses are careful about the idea. Banks are attempting earnest endeavours to advance the e-saving money administrations and items. The more youthful age is starting to see the accommodation and advantages if e-saving money. In years to come, e-keeping money won't just be the adequate method of managing an account, however, will be the favoured method of saving money. 


\section{References}

1. Bikram Jit Singh Mann \& Sunpreet Kaur Sahni. (2012). Profiling Adopter Categories of Internet Banking in India: An Empirical Study. Vision (09722629).

2. Nayak, Raghvendra. (2018). A Conceptual study on digitalization of banking-issues and challenges. International Journal of Management, IT \& Engineering, 8(6), 186-191.

3. Teena, Shivnani. (2015). Investigating the drivers of internet banking adoption decision: A comparison of three alternative frameworks. 